\title{
Numerical Study of Natural Convection in a Two-Dimensional Enclosure with a Sinusoidal Boundary Thermal Condition Utilizing Nanofluid
}

\author{
Ibtissam El Bouihi, Rachid Sehaqui \\ Mechanical Laboratory, Faculty of Sciences Aïn Chock, Hassan II University, Casablanca, Morocco \\ Email: i.elbouihi@hotmail.com
}

Received May 17, 2012; revised June 18, 2012; accepted July 4, 2012

\begin{abstract}
Nanofluids are considered to offer important advantages over conventional heat transfer fluids. A model is developed to analyze the behavior of nanofluids taking into account the solid fraction $\chi$. The Navier-Stokes equations are solved numerically with Alternating Direct Implicit method (ADI method) for various Grashof numbers $10^{4}$ and $10^{5}$; we have an excellent agreement between our numerical code and previously published works. Copper-Water nanofluid is used with $\operatorname{Pr}=6.2$ and solid volume fraction $\chi$ is varied as $0 \% ; 5 \% ; 10 \% ; 15 \%$ and $20 \%$. The problem considered is a two-dimensional heat transfer in a square cavity. The vertical walls are differentially heated, the left is maintained at hot condition (sinusoidal) when the right one is cold. The horizontal walls are assumed to be insulated, non conducting and impermeable to mass transfer. The nanofluid in the enclosure is Newtonian, incompressible and laminar. The nanoparticles are assumed to have a uniform shape and size. Moreover, it is assumed that both the fluid phase and nanoparticles are in thermal equilibrium state and they flow at the same velocity. The thermophysical properties of the nanofluid are assumed to be constant except for the density variation in the buoyancy force, which is based on the Boussinesq approximation. Different correlations are proposed for predicting heat transfer for uniform and sinusoidal boundary thermal conditions.
\end{abstract}

Keywords: Nanofluid; Natural Convection; Numerical Study; Solid Volume Fraction

\section{Introduction}

In recent years, fluids containing suspension of nanometer-sized particles (nanofluids) have been an active area of research thanks to their enhanced thermal properties over the base fluids. This makes them very attractive as heat transfer fluids in many applications such as coolants in the automobile and electronics industries, and manufacturing processes. In a better description, nanofluids are engineered colloidal suspensions of nanoparticles (1 $100 \mathrm{~nm}$ ) in a base fluid. Common base fluids include water and organic liquids while nanoparticles are typically made of chemically stable metals, metal oxides or carbon in various forms. The size of the nanoparticles imparts some unique characteristics to these fluids, including greatly enhanced energy, momentum and mass transfer, as well as reduced tendency for sedimentation and erosion of the containing surfaces. Nanofluids are being investigated for numerous applications, including cooling, manufacturing, chemical and pharmaceutical processes, medical treatments, cosmetics, etc.
All the studies on thermal conductivity of suspensions have been confined to millimeter- or micrometer-sized particles. The major problem with suspensions containing millimeter- or micrometer-sized particles is the rapid settling of these particles. Furthermore, such particles are too large for micro systems.

However, modern nanotechnology provides great opportunities to process and produce materials with average crystallite sizes below $50 \mathrm{~nm}$. Recognizing an opportunity to apply this emerging nanotechnology to established thermal energy engineering.

The use of particles of nanometer dimension was first continuously studied by a research group at the Argonne National Laboratory a decade ago. S. Choi [1] in 1995 was probably the first one who called the fluids with particles of nanometer dimensions "nanofluids", he showed substantial augmentation of heat transported in suspendsions of copper or aluminum nanoparticles in water and other liquids. Compared with suspended particles of millimeter or micrometer dimensions, nanofluids show better stability and rheological properties, dramatically higher 
thermal conductivities and no penalty in pressure drop. Several published literature have mainly focused on the prediction and measurement techniques in order to evaluate the thermal conductivity of nanofluid. It is noticeable that only a few papers have discussed the convective heat transfer of nanofluids, including the experimental and theoretical investigation.

The problem of natural convection flow and heat transfer of Newtonian alumina-water nanofluids over a vertical semi-infinite plate was investigated by Polidori et al. [2] from a theoretical view-point for a range of nanoparticle volume fractions up to $4 \%$. The Polidori's study focused only on the effect of the viscosity. Hwang et al. [3] investigated natural convection instability and heat transfer characteristics of water- $\mathrm{Al}_{2} \mathrm{O}_{3}$ nanofluids in the rectangular cavity heated from below. They estimate that the ratio of heat transfer coefficient exist between the two lines calculated by Einstein's model and Pak and Cho's correlation. Instability of natural convection for nanofluids between two plates, heated from below, was studied by Tzou [4].

$\mathrm{Li}$ and Xuan [5] presented an experimental system to investigate the heat transfer coefficient and friction factor of nanofluids for laminar and turbulent flow in a tube.

Buoyancy induced that flow and heat transfer is an important phenomenon in engineering systems due to its wide applications in electronic cooling, heat exchangers, double pane windows etc. For energy saving reasons, enhancing heat transfer in these systems is an essential topic. The low thermal conductivity of convectional heat transfer fluids such as water and oils is a primary limitation in enhancing the performance and the compactness of such systems. Nanotechnology has been widely used in industry since materials with sizes of nanometers possess unique physical and chemical properties. Nano-scale particle added fluids are called nanofluid. Yang et al. [6] concluded experimentally that the type of nanoparticles, particle loading, base fluid chemistry, and process temperature are all important factors to be considered while developing nanofluids for high heat transfer coefficients. Experimental work by Wen et al. [7] investigate into convective heat transfer of nanofluids at the entrance region under laminar flow conditions. Some numerical studies on nanofluids include thermal conductivity [8]. Studies on natural convection using nanofluids are very limited and they are related with differentially heated enclosures. Khanafer et al. [9] tested different models for nanofluid density, viscosity and thermal expansion coefficients.

In the present work, we simulate the flow features of nanofluids for a range of solid volume fraction $\chi$ and a sinusoidal thermal boundary condition, and we obtained correlations of heat transfer in enclosures for two different thermal boundary conditions on the left wall.

\section{Mathematical Description of the Problem}

The problem considered is a two-dimensional heat transfer in a square cavity (Figure 1). The vertical walls are differentially heated, the right wall is cold $\left(T_{c}\right)$ while left is heated with a sinusoidal temperature (Figure 2) $\left(T_{h}=T_{c}+\frac{\Delta T}{2}\left(1-\cos \frac{2 \pi y^{*}}{H}\right)\right)$. The horizontal walls are assumed to be insulated, non conducting and impermeable to mass transfer. The nanofluid in the enclosure is Newtonian, incompressible and laminar. The nanoparticles are assumed to have a uniform shape and size. Moreover, it is assumed that both the fluid phase and nanoparticles are in thermal equilibrium state and flow at the same velocity. The thermo-physical properties of the nanofluid are assumed to be constant (Table 1) except for the density variation in the buoyancy force, which is based on the Boussinesq approximation.

Under the assumption of constant thermal properties, the Navier-Stokes equation for an unsteady, incompressible, two-dimensional flow are:

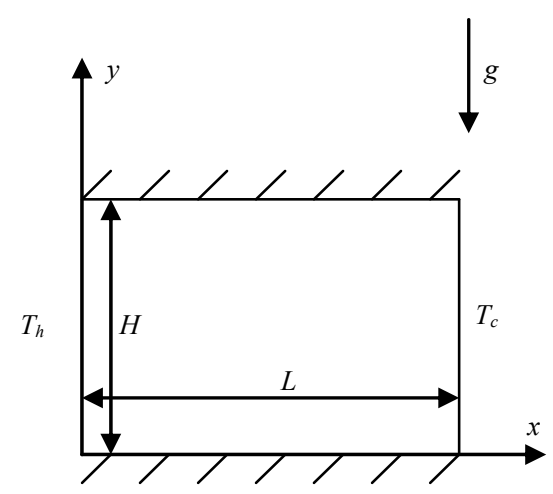

Figure 1. Schematic for the physical model.

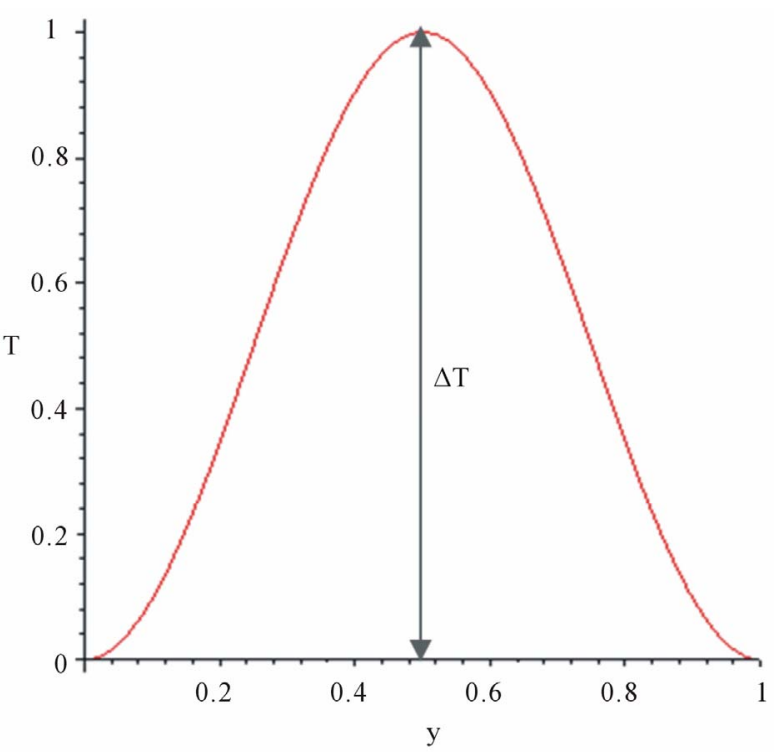

Figure 2. Dimensionless temperature profile of the left wall. 
Table 1. Thermophysical properties of different phases.

\begin{tabular}{ccc}
\hline Property & Fluid phase (water) & Solid phase (copper) \\
\hline $\mathrm{Cp}(\mathrm{J} / \mathrm{kg} \cdot \mathrm{K})$ & 4179 & 383 \\
$\rho\left(\mathrm{kg} / \mathrm{m}^{3}\right)$ & 997.1 & 8954 \\
$k(\mathrm{~W} / \mathrm{m} \cdot \mathrm{K})$ & $2.1 \times 10^{-4}$ & $1.67 \times 10^{-5}$ \\
\hline
\end{tabular}

- Continuity equation:

$$
\frac{\partial u^{*}}{\partial x^{*}}+\frac{\partial v^{*}}{\partial y^{*}}=0
$$

- $x$-momentum equation:

$$
\begin{aligned}
& \frac{\partial u^{*}}{\partial t^{*}}+u^{*} \frac{\partial u^{*}}{\partial x^{*}}+v^{*} \frac{\partial u^{*}}{\partial y^{*}} \\
& =-\frac{1}{\rho_{n f, 0}} \frac{\partial p^{*}}{\partial x^{*}}+\frac{\mu_{e f f}}{\rho_{n f, 0}}\left(\frac{\partial^{2} u^{*}}{\partial x^{* 2}}+\frac{\partial^{2} u^{*}}{\partial y^{* 2}}\right)
\end{aligned}
$$

- $y$-momentum equation:

$$
\begin{aligned}
& \frac{\partial v^{*}}{\partial t^{*}}+u^{*} \frac{\partial v^{*}}{\partial x^{*}}+v^{*} \frac{\partial v^{*}}{\partial y^{*}} \\
& =-\frac{1}{\rho_{n f, 0}} \frac{\partial p^{*}}{\partial y^{*}}+\frac{\mu_{e f f}}{\rho_{n f, 0}}\left(\frac{\partial^{2} v^{*}}{\partial x^{* 2}}+\frac{\partial^{2} v^{*}}{\partial y^{* 2}}\right) \\
& +\frac{1}{\rho_{n f, 0}}\left[\chi \rho_{s, 0} \beta_{s}+(1-\chi) \rho_{f, 0} \beta_{f}\right] g\left(T-T_{c}\right)
\end{aligned}
$$

- Energy equation:

$$
\frac{\partial T^{*}}{\partial t^{*}}+u^{*} \frac{\partial T^{*}}{\partial x^{*}}+v^{*} \frac{\partial T^{*}}{\partial y^{*}}=\alpha_{n f}\left(\frac{\partial^{2} T^{*}}{\partial x^{* 2}}+\frac{\partial^{2} T^{*}}{\partial y^{* 2}}\right)
$$

where $\alpha_{n f}=\frac{k_{e f f}}{\left(\rho C_{p}\right)_{n f, 0}}$.

The effective viscosity of fluid containing a dilute suspension of small rigid spherical particles is given by Brinkman [10] as

$$
\mu_{e f f}=\frac{\mu_{f}}{(1-\chi)^{2.5}}
$$

The effective density of the nanofluid at reference temperature is

$$
\rho_{n f, 0}=(1-\chi) \rho_{f, 0}+\chi \rho_{s, 0}
$$

and the heat capacitance of nanofluid is

$$
\left(\rho C_{p}\right)_{n f, 0}=(1-\chi)\left(\rho C_{p}\right)_{f, 0}+\chi\left(\rho C_{p}\right)_{s, 0}
$$

The effective thermal conductivity of fluid can be determined by Maxwell-Garnett's (MG model) self-consistent approximation model. For the two-component entity of spherical-particle suspension, the MG model gives

$$
\frac{k_{e f f}}{k_{f}}=\frac{\left(k_{s}+2 k_{f}\right)-2 \chi\left(k_{f}-k_{s}\right)}{\left(k_{s}+2 k_{f}\right)+\chi\left(k_{f}-k_{s}\right)}
$$

Boundary conditions:

for $x^{*}=0$ and $0 \leq y^{*} \leq H, u^{*}=v^{*}=0$ and $T^{*}=T_{h}=T_{c}+\frac{\Delta T}{2}\left(1-\cos \frac{2 \pi y^{*}}{H}\right)$

for $x^{*}=L$ and $0 \leq y^{*} \leq H, u^{*}=v^{*}=0$ and $T^{*}=T_{c}$ for $y^{*}=0$ or $y^{*}=H$ and $0 \leq x^{*} \leq L$,

$u^{*}=v^{*}=\frac{\partial T^{*}}{\partial y^{*}}=0$.

The above equations can be converted to non-dimensional form, using the following dimensionless parameters:

$$
x=\frac{x^{*}}{H}, \quad y=\frac{y^{*}}{H}, \quad u=\frac{u^{*}}{V_{0}}, \quad v=\frac{v^{*}}{V_{0}}, \quad p=\frac{p^{*}}{\rho V_{0}^{2}},
$$$$
t=\frac{t^{*} V_{0}}{H}, T=\frac{T^{*}-T_{c}}{\Delta T}, \quad \mathrm{Gr}=\frac{g \beta H^{3} \Delta T}{v_{f}^{2}}, \operatorname{Pr}=\frac{v_{f}}{\alpha_{f}}
$$

where $\Delta T=T_{h}-T_{c}$ and $V_{0}=\frac{\mu_{e f f}}{\rho_{n f, 0} H}$.

The governing equations can be written in dimensionless form as follows:

- Continuity equation:

$$
\frac{\partial u}{\partial x}+\frac{\partial v}{\partial y}=0
$$

- $x$-momentum equation:

$$
\frac{\partial u}{\partial t}+u \frac{\partial u}{\partial x}+v \frac{\partial u}{\partial y}=\frac{\partial p}{\partial x}+\left(\frac{\partial^{2} u}{\partial x^{2}}+\frac{\partial^{2} u}{\partial y^{2}}\right)
$$

- $y$-momentum equation:

$$
\begin{aligned}
& \frac{\partial v}{\partial t}+u \frac{\partial v}{\partial x}+v \frac{\partial v}{\partial y}=-\frac{\partial p}{\partial y}+\left(\frac{\partial^{2} v}{\partial x^{2}}+\frac{\partial^{2} v}{\partial y^{2}}\right) \\
& +\frac{\rho_{n f, 0} v_{f}^{2}}{\beta_{f} \mu_{e f f}^{2}}\left[\chi \rho_{s, 0} \beta_{s}+(1-\chi) \rho_{f, 0} \beta_{f}\right] \mathrm{Gr} T
\end{aligned}
$$

- Energy equation:

$$
\frac{\partial T}{\partial t}+u \frac{\partial T}{\partial x}+v \frac{\partial T}{\partial y}=\frac{1}{\operatorname{Pr}_{n f}}\left(\frac{\partial^{2} T}{\partial x^{2}}+\frac{\partial^{2} T}{\partial y^{2}}\right)
$$

where $\operatorname{Pr}_{n f}=\frac{\mu_{e f f}}{\alpha_{n f} \rho_{n f, 0}}$.

Boundary conditions are for $x=0$ and $0 \leq y \leq 1, u=v=0$ and $T=\frac{1}{2}(1-\cos 2 \pi y)$ 
for $x=1$ and $0 \leq y \leq 1, u=v=0$ and $T=0$

for $y=0$ or $y=1$ and $0 \leq x \leq 1, u=v=\frac{\partial T}{\partial y}=0$

The governing equations for the present study in $(\psi, \omega)$ formulaton taking into the account the above mentioned assumptions are written in dimensionless form as

- Kinematics equation

$$
\frac{\partial^{2} \psi}{\partial x^{2}}+\frac{\partial^{2} \psi}{\partial y^{2}}=-\omega
$$

- Vorticity equation

$$
\begin{aligned}
& \frac{\partial \omega}{\partial t}+u \frac{\partial \omega}{\partial x}+v \frac{\partial \omega}{\partial y}=\left(\frac{\partial^{2} \omega}{\partial x^{2}}+\frac{\partial^{2} \omega}{\partial y^{2}}\right) \\
& +\frac{\rho_{n f, 0} v_{f}^{2}}{\beta_{f} \mu_{e f f}^{2}}\left[\chi \rho_{s, 0} \beta_{s}+(1-\chi) \rho_{f, 0} \beta_{f}\right] \mathrm{Gr} \frac{\partial T}{\partial x}
\end{aligned}
$$

where $u=\frac{\partial \psi}{\partial y}, v=-\frac{\partial \psi}{\partial x}$ and $\omega=-\nabla^{2} \psi$.

Dimensionneless boundary conditions for $(\psi, \omega)$ are: For $x=0, x=1$ and $0 \leq y \leq 1, \psi=0$ and

$\omega=-\frac{\partial^{2} \psi}{\partial x^{2}}$.

For $y=0, y=1$ and $0 \leq x \leq 1, \psi=0$ and $\omega=-\frac{\partial^{2} \psi}{\partial y^{2}}$.

The Nusselt number of the nanofluids is expected to depend on a number of factors such as thermal conductivity and heat capacitance of both the pure fluid and the ultrafine particles, the volume fraction of the suspended particles, the flow structure and the viscosity of the nanofluid. The local variation of the Nusselt number of the nanofluid can be expressed as

$$
\mathrm{Nu}=-\frac{k_{e f f}}{k_{f}} \frac{\partial T}{\partial x}
$$

\section{Numerical Method}

The governing equations are solved numerically by ADI method (Alternating Direct Implicit). The developped numerical code is validated for natural convection heat transfer by comparing the results a laminar heat transfer in a square cavity with air for Rayleigh numbers between $10^{3}$ and $10^{6}$ (Table 2). Moreover, the present numerical code was also validated against the experimental results of Santra and Sen [11] and numerical of Tiwari and Das [12] for natural convection in a differentially heated square enclosure using nanofluids (Figure 3), a very good agreement is obtained.

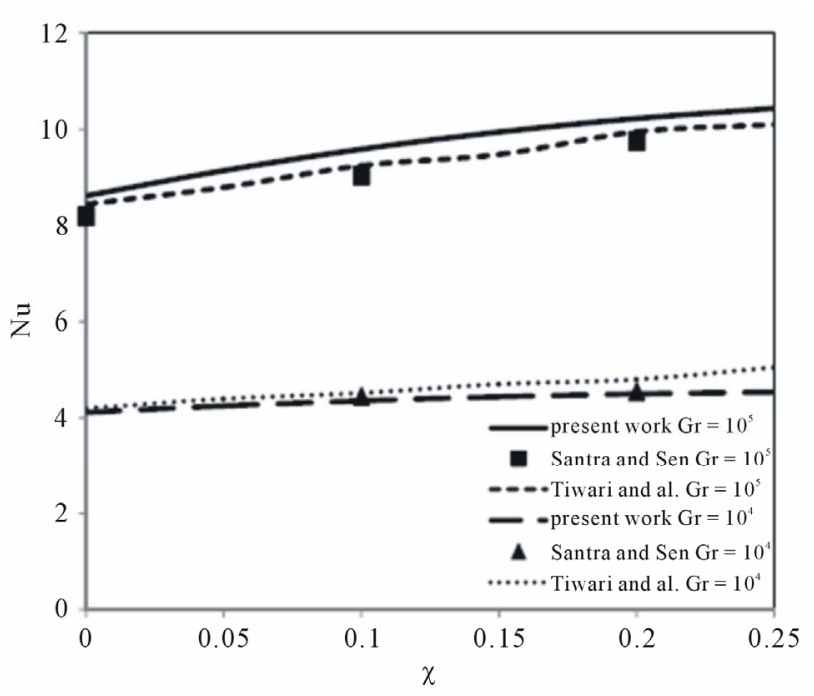

Figure 3. Validation of numerical code with results of Santra and Sen [11] and Tiwari and Das [12].

The grid independence test is performed using successively sized grids, $31 \times 31,41 \times 41,61 \times 61,81 \times 81$ and $101 \times 101$ for $\mathrm{Gr}=10^{5}, \operatorname{Pr}=6.2$ and $\chi=10 \%$. Uniform grid has been used for all the computations. The distribution of the $u$-velocity in the vertical mid-plane and temperature and $v$-velocity in the horizontal midplane are shown in Figure 4. It is observed that the curves overlap with each other for $81 \times 81$ and $101 \times 101$. So a grid number of $81 \times 81$ is chosen for further computation.

\section{Results and Discussion}

\subsection{Comparative Study}

For pure fluid, we observe (Figure 5) for a sinusoidal boundary thermal condition on the left wall, a conductive scheme at $\mathrm{Ra}=10^{3}$. However beyond this value, the convective scheme begins.

The numerical code developed in the present investigation is used to carry out a number of simulations for a wide range of controlling parameters such as Grashof number and the volume fraction of particles. A comparison of the temperature and the velocity profiles is conducted inside a thermal cavity with isothermal vertical walls at various Grashof numbers and volume fractions as shown in Figure 6. This figure shows that the nanofluid behaves like a fluid and it illustrates the effect of Grashof number and the volume fraction on the temperature and the velocity profiles at the mid-sections of the cavity for water with a Prandtl number of 6.2. The numerical results of the present study indicate that the heat transfer feature of a nanofluid increases remarkably with the volume fraction of nanoparticles. As the volume fraction increases, irregular and random movements of 

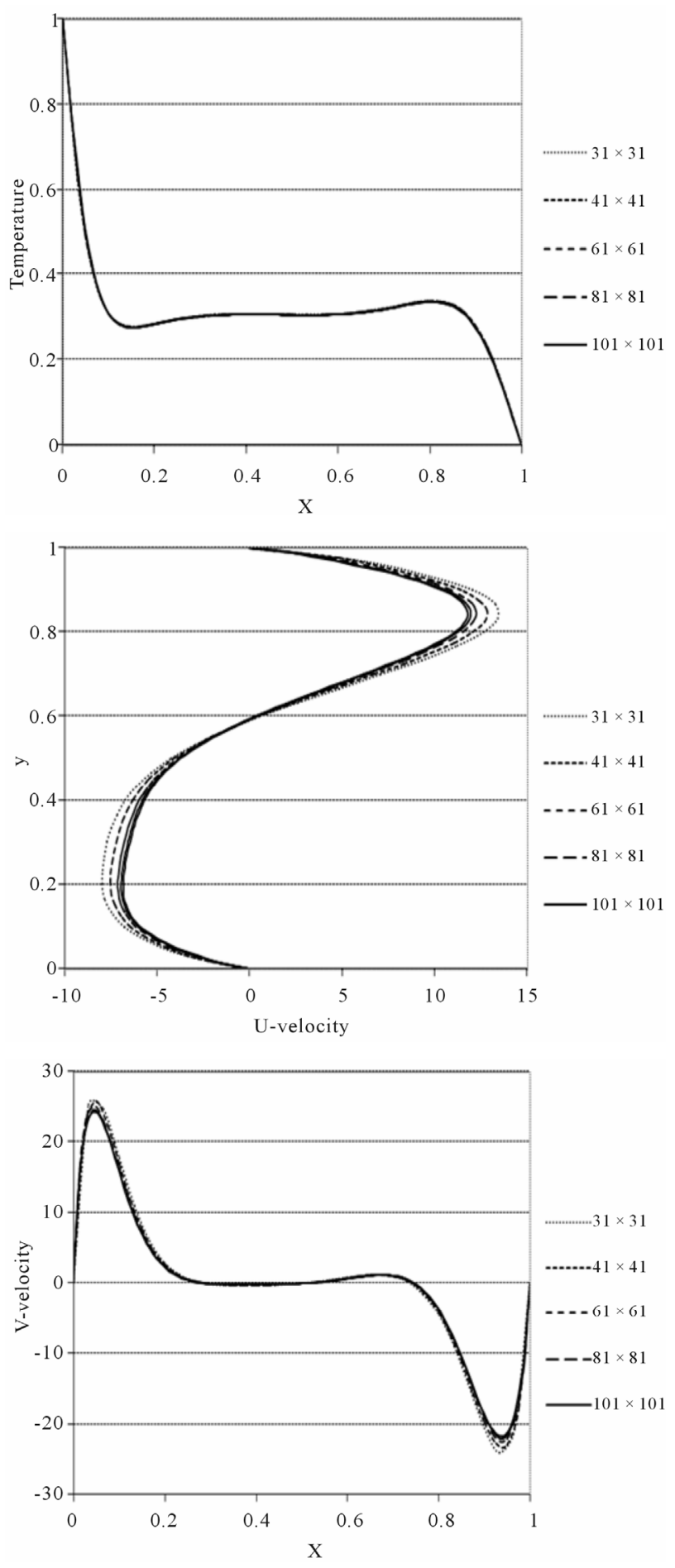

Figure 4. Temperature and velocity profiles at mid-sections of the cavity for various meshes sizes $(\mathrm{Gr}=105, \mathrm{Pr}=6.2, \mathrm{~T}=$ $1 / 2(1-\cos 2 \pi y)$ and $\chi=10 \%)$.

particles increases energy exchange rates in the fluid and consequently enhances the thermal dispersion in the flow of nanofluid.

The effect of the volume fraction on the streamlines and isotherms of nanofluid for various Grashof numbers
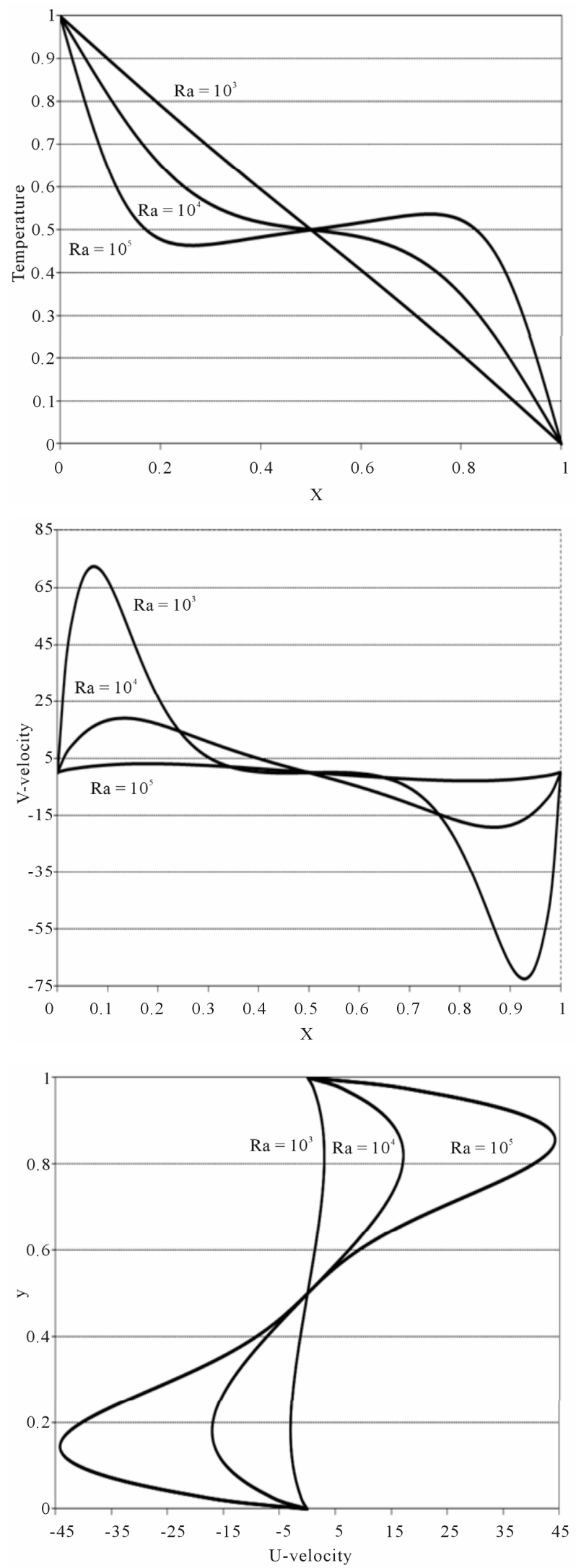

Figure 5. Temperature and velocity profiles at the midsections of the cavity $(\operatorname{Pr}=6.2$ and $T=1 / 2(1-\cos 2 \pi y))$. 
Table 2. Comparison of Nusselt number with previous works.

\begin{tabular}{|c|c|c|c|c|c|c|c|c|}
\hline & $\begin{array}{c}\text { Present } \\
\text { work (a) }\end{array}$ & $\begin{array}{l}\text { Khanafer } \\
\text { et al. [6] }\end{array}$ & $\begin{array}{c}\text { Tiwari } \\
\text { et al. [12] }\end{array}$ & $\begin{array}{l}\text { Barakos } \\
\text { et al. [13] }\end{array}$ & $\begin{array}{l}\text { Markatos } \\
\text { et al. }[14]\end{array}$ & $\begin{array}{c}\text { Fusegi } \\
\text { et al. [15] }\end{array}$ & $\begin{array}{c}\text { De Vahl } \\
\text { Davis [16] (b) }\end{array}$ & $\frac{b-a}{b} \times 100$ \\
\hline \multicolumn{9}{|c|}{$\mathrm{Ra}=10^{3}$} \\
\hline \multicolumn{9}{|c|}{$\mathrm{Ra}=10^{4}$} \\
\hline$\overline{\mathrm{Nu}}$ & 2.024 & 2.245 & 2.197 & 2.245 & 2.201 & 2.302 & 2.243 & $9.76 \%$ \\
\hline \multicolumn{9}{|c|}{$\mathrm{Ra}=10^{5}$} \\
\hline$\overline{\mathrm{Nu}}$ & 4.520 & 4.522 & 4.450 & 4.510 & 4.430 & 4.646 & 4.519 & $0.02 \%$ \\
\hline \multicolumn{9}{|c|}{$\mathrm{Ra}=10^{6}$} \\
\hline$\overline{\mathrm{Nu}}$ & 8.978 & 8.826 & 8.803 & 8.806 & 8.754 & 9.012 & 8.799 & $2.03 \%$ \\
\hline
\end{tabular}
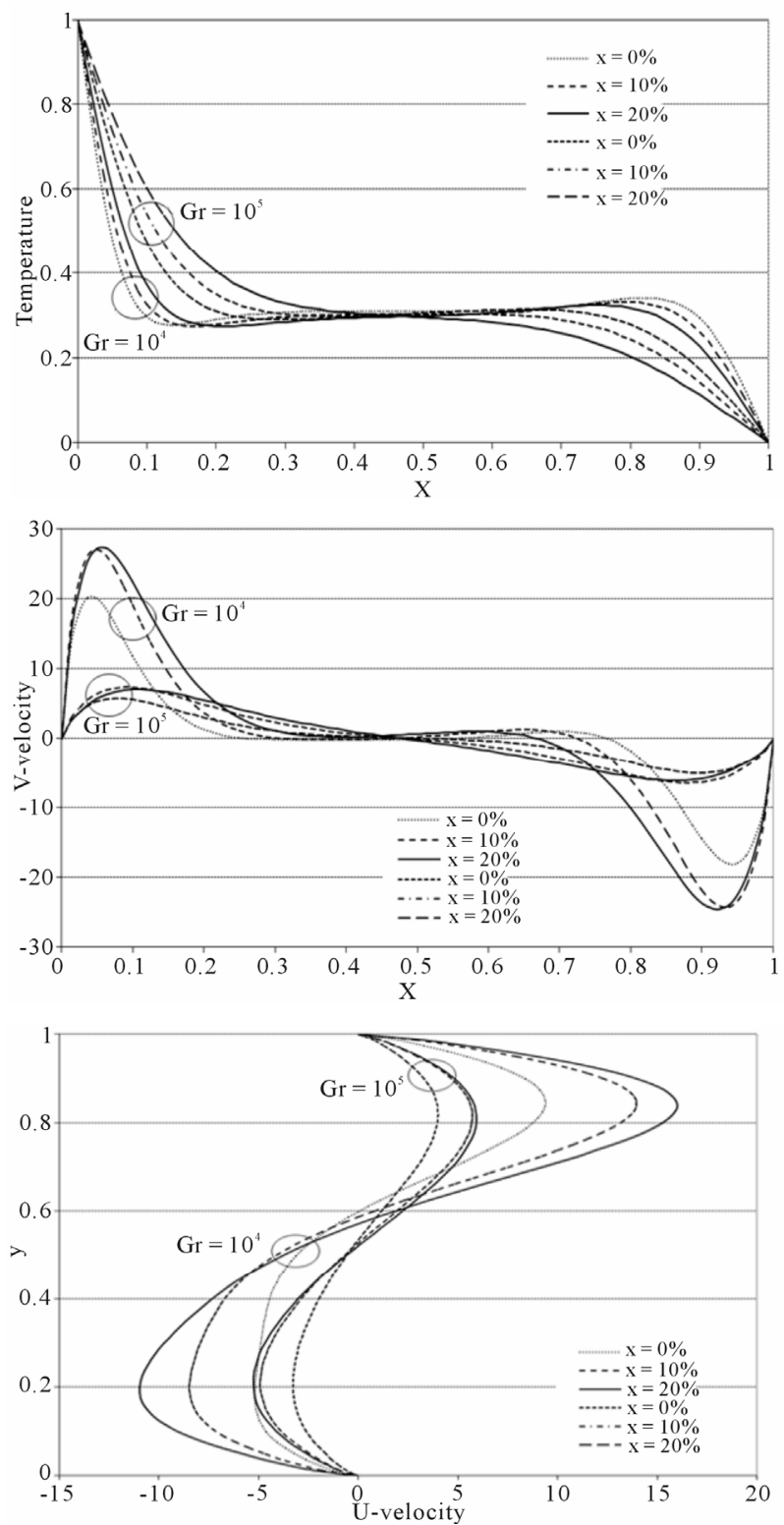

Figure 6. Comparison of the temperature and velocity profiles between nanofluid and pure fluid for various Grashof numbers; $\operatorname{Pr}=6.2$ and $T=1 / 2(1-\cos 2 \pi y)$.

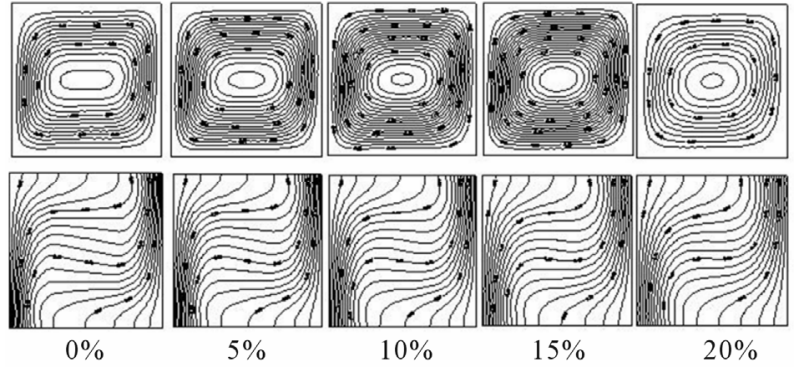

Figure 7. Streamlines contours and isotherms at various volume fractions $\left(\mathrm{Gr}=10^{4} ; \operatorname{Pr}=6.2\right.$ and $\left.T=1\right)$.

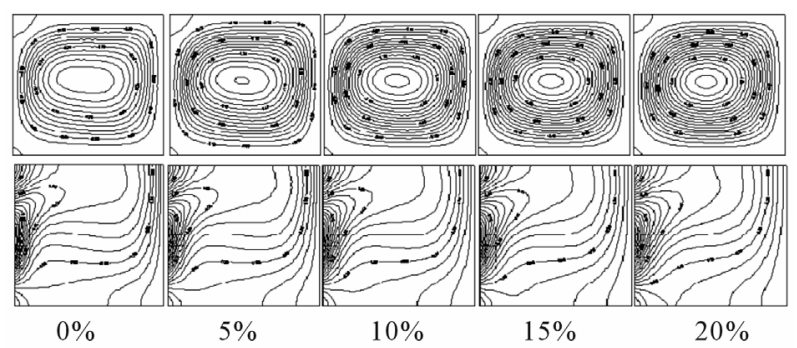

Figure 8. Streamlines contours and isotherms at various volume fractions $\left(\mathrm{Gr}=10^{4} ; \operatorname{Pr}=6.2\right.$ and $\left.T=1 / 2(1-\cos 2 \pi y)\right)$.

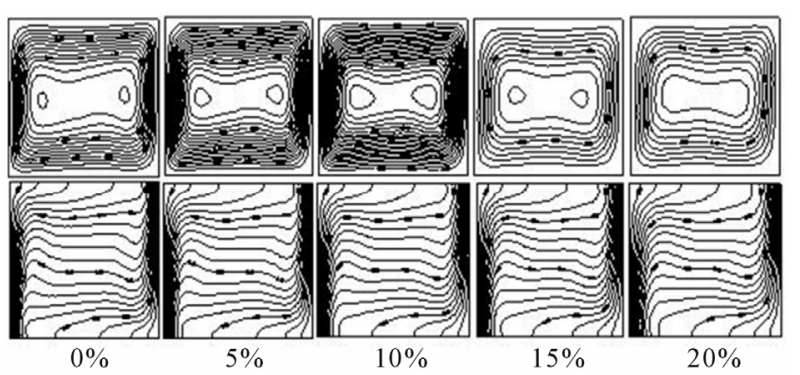

Figure 9. Streamlines contours and isotherms at various volume fractions $\left(\mathrm{Gr}=10^{5} ; \mathrm{Pr}=6.2\right.$ and $\left.T=1\right)$.

is shown for $T=1$ in Figures 7 and 9 and for $T=1 / 2(1-$ $\cos 2 \pi y$ ) in Figures 8 and 10. They show that the intensity of the streamlines increase with an increase in the volume fraction as a result of high-energy transport through the flow associated with the irregular motion of 


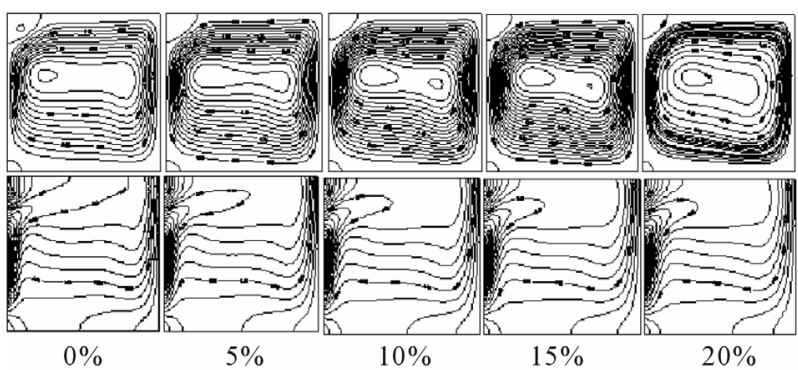

Figure 10. Streamlines contours and isotherms at various volume fractions $\left(\mathrm{Gr}=10^{5} ; \operatorname{Pr}=6.2\right.$ and $\left.T=1 / 2(1-\cos 2 \pi y)\right)$.

the ultrafine particles. The isotherms show that the vertical stratification of isotherms breaks down with an increase in the volume fraction for higher Grashof numbers. This is due to a number of effects such as gravity, Brownian motion.

\subsection{Heat Transfer Correlation}

The experimental results illustrate that the convective heat transfer coefficient of the nanofluids varied with the flow velocity and volume fraction as well as being higher than the base fluid at the same conditions. From this numerical study, new heat transfer correlation for prediction of heat transfer coefficient of nanofluids flowing can be estabilished in the following form for:

- A differentially heated square cavity with uniforme temperature on the left wall

$$
\begin{aligned}
\mathrm{Nu}= & \left(26.66 \chi^{4}-10.66 \chi^{3}+1.133 \chi^{2}\right. \\
& +0.046 \chi+0.18) \mathrm{Gr}^{(0.04 \chi+0.322)}
\end{aligned}
$$

where the confidence coefficient of the above equation is determined as $R^{2}=99.99 \%$.

- A differentially heated square cavity with sinusoidal temperature on the left wall

$$
\begin{aligned}
\mathrm{Nu}= & \left(-0.6 \chi^{3}-0.0429 \chi^{2}+0.0441 \chi+0.0754\right) \\
& \mathrm{Gr}^{\left(0.8 \chi^{3}-0.0714 \chi^{2}+0.0193 \chi+0.3425\right)}
\end{aligned}
$$

where the confidence coefficient of the above equation is determined as $R^{2}=99.99 \%$.

A linear variation of the average Nusselt number along the hot wall from the correlations and the numerical results for various Grashof numbers and volume fractions is shown in Figures 11(a) and (b) for the two thermal boundary conditions.

\section{Conclusions}

In this paper, the heat transfer enhancement in a twodimensional enclosure filled with nanofluids is studied numerically. This study has been performed to investigate the effect of using a uniform thermal boundary condition

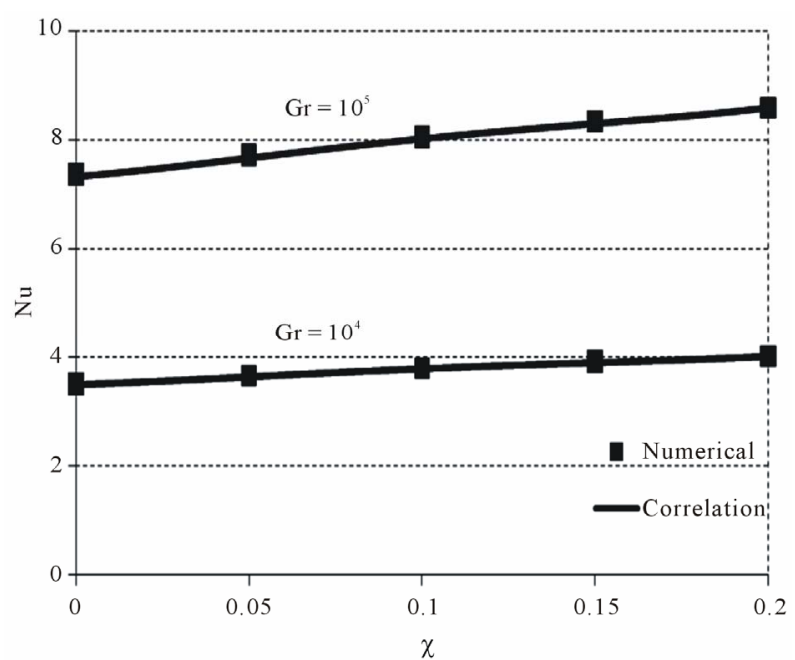

(a)

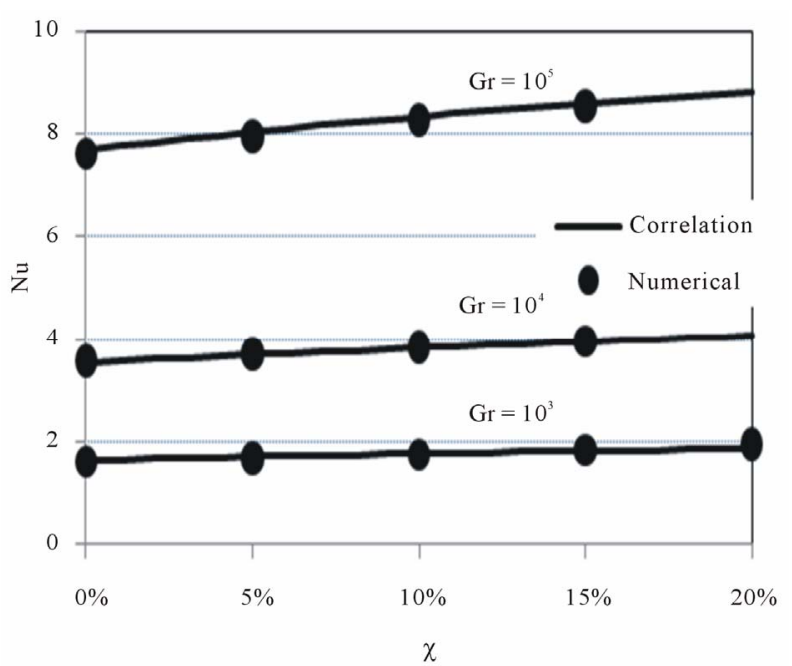

(b)

Figure 11. Comparison of the average Nusselt number between the numerical results and that obtained by the correlations $(\operatorname{Pr}=6.2$ and (a) $T=1$; (b) $T=1 / 2(1-\cos 2 \pi y))$.

and a sinusoidal one for a range of Grashof numbers and volume fractions of nanoparticles. Some important points are carried out:

1) Our inhouse numerical code was validated for different Rayleigh numbers.

2) A comparative study illustrates that the suspended nanoparticles substantially increase the heat transfer rate with an increase in the nanoparticles volume fraction for any Grashof number. Moreover, the nanofluid flows as well as the cooper nanoparticles increase.

3 ) Both pure water and the nanofluid have the same velocity profiles and the same behavior for different Grashof numbers.

A heat transfer correlation for the nanofluid cooperwater is obtained and verified for various Grashof numbers and volume fractions for both thermal boundary 
conditions.

\section{REFERENCES}

[1] S. U. S. Choi and J. A. Eastman, "Enhancing Thermal Conductivity of Fluids with Nanoparticles, Developments and Applications of Non-Newtonian Flows," In: D. A. Siginer and H. P. Wang, Eds., American Society of Mechanical Engineers, New York, 1995, pp. 99-105.

[2] G. Polidori, S. Fohanno and C. T. Nguyen, "A Note on Heat Transfer Modelling of Newtonian Nanofluids in Laminar Free Convection," International Journal of Thermal Sciences, Vol. 46, No. 8, 2007, pp. 739-744. doi:10.1016/j.ijthermalsci.2006.11.009

[3] K. S. Hwang, J. Lee and S. P. Jang, "Buoyancy-Driven Heat Transfer of Water-Based $\mathrm{Al}_{2} \mathrm{O}_{3}$ Nanofluids in a Rectangular Cavity," International Journal of Heat and Mass Transfer, Vol. 50, No. 19-20, 2007, pp. 4003-4010. doi:10.1016/i.ijheatmasstransfer.2007.01.037

[4] D. Y. Tzou, "Thermal Instability of Nanofluids in Natural Convection," International Journal of Heat and Mass Transfer, Vol. 55, No. 11-12, 2008, pp. 2967-2979. doi:10.1016/j.ijheatmasstransfer.2007.09.014

[5] Q. Li and Y. Xuan, "Heat transfer Enhancement of Nanofluids," International Journal of Heat and Fluid Flow, Vol. 21, No. 1, 2000, pp. 58-64. doi:10.1016/S0142-727X(99)00067-3

[6] Y. Yang, Z. G. Zhang, E. A. Grulke, W. B. Anderson and G. Wu, "Heat Transfer Properties of Nanoparticle-inFluid Dispersions (Nanofluids) in Laminar Flow," International Journal of Heat and Mass Transfer, Vol. 48, No. 6, 2005, pp. 1107-1116. doi:10.1016/j.ijheatmasstransfer.2004.09.038

[7] D. Wen and Y. Ding, "Experimental Investigation into Convective Heat Transfer of Nanofluids at the Entrance Region under Laminar Flow Conditions," International Journal of Heat and Mass Transfer, Vol. 47, No. 24, 2004, pp. 5181-5188. doi:10.1016/j.ijheatmasstransfer.2004.07.012

[8] C. Nie, W. H. Marlow and Y. A. Hassan, "Discussion of Proposed Mechanisme of Thermal Conductivity Enhance- ment in Nanofluids," International Journal of Heat and Mass Transfer, Vol. 51, 2008, pp. 1342-1348.

doi:10.1016/j.ijheatmasstransfer.2007.11.034

[9] K. Khanafer, K. Vafai and M. Lightstone, "BuoyancyDriven Heat Transfer Enhancement in a Two-Dimensional Enclosure Utilizing Nanofluids," International Journal of Heat and Mass Transfer, Vol. 46, No. 19, 2003, pp. 3639-3653. doi:10.1016/S0017-9310(03)00156-X

[10] H. C. Brinkman, "The Viscosity of Concentrated Suspensions and Solutions," Journal of Chemical and Physics, Vol. 20, No. 4, 1952, pp. 571-581. doi:10.1063/1.1700493

[11] A. K. Santra, S. Sen and N. Chakraborty, "Analysis of Laminar Natural Convection in a Square Cavity Using Nanofluid," Proceedings of the 31st National Conference of Fluid Mechanics and Fluid Power, Jadavpur, 11-13 December 2004, pp. 240-248.

[12] R. K. Tiwari and M. K. Das, "Heat Transfer Augmentation in a Two-Sided Lid-Driven Differentially Heated Square Cavity Utilizing Nanofluids," International Journal of Heat and Mass Transfer, Vol. 50, No. 9-10, 2007, pp. 2002-2018. doi:10.1016/j.ijheatmasstransfer.2006.09.034

[13] G. Barakos and E. Mitsoulis, "Natural Convection Flow in a Square Cavity Revisited: Laminar and Turbulent Models with Wall Functions," International Journal of Numerical Methods Fluids, Vol. 18, No. 7, 1994, pp. 695719. doi:10.1002/fld.1650180705

[14] N. C. Markatos and K. A. Pericleous, "Laminar and Turbulent Natural Convection in an Enclosed Cavity," International Journal of Heat and Mass Transfer, Vol. 27, No. 5, 1984, pp. 755-772. doi:10.1016/0017-9310(84)90145-5

[15] T. Fusegi, K. Kuwahara and B. Farouk, "A Numerical Study of Three-Dimensional Natural Convection in a Differentially Heated Cubic Enclosure," International Journal of Heat and Mass Transfer, Vol. 34, No. 6, 1991, pp. 1543-1557. doi:10.1016/0017-9310(91)90295-P

[16] G. De Vahl Davis, "Natural Convection of Air in a Square Cavity: A Benchmark Solution," International Journal of Numerical Methods Fluids, Vol. 3, No. 3, 1983, pp. 249-264. doi:10.1002/fld.1650030305 